\title{
Fluorometric Determination of Uranium in Environmental Materials
}

by

James W. Owens

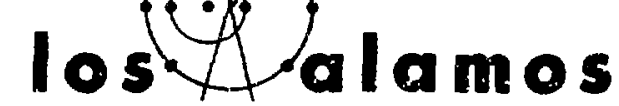

scientific laboratory

of the University of California

los alAMOS, NEW MEXICO 87545

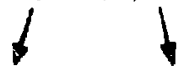

An Aflirmative Acsion / Equal Opportunity Employer 
Printed in the United States of Amcrica. Available from National Technical Information Service

U.S. Department of Commerce

5285 Port Royal Road

Springfield, VA 22161

Price: Printed Copy $\$ 3.50$ Microfiche $\$ 2.25$ 


\section{FLUOROHETRIC OETERMIHATIOH OF URAHIUM IN ENVIROHMEHTAL MATERIALS}

by

James H. Owens

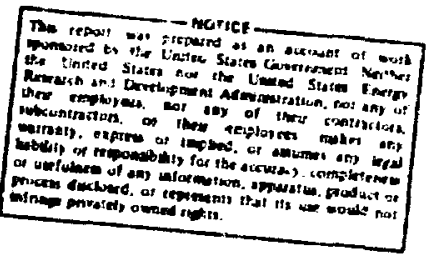

\section{ABSTRACT}

This report describes the fused fluoride nellet fluorometric method of uranium tetermination used at the Los Alamos Scientific Laboratory for the measurement of uranium in environmental samples with concentrations as low as 0.1 ppb lotal $U$. These anaalytical techniques are routinely used in the analysis of thossands of samples of soils, natural waters. and various biological malerials.

\section{INTRODUCTION}

The analytical chemistry of uranium was extensively investigated as part of the Manhatton Project. I Since then a wide variety of measurement techniques have been developed: gravimetric. ${ }^{2}$ volumetric. ${ }^{3}$ colorimetric, ${ }^{4}$ coulometric, 5 polaroqraphic, 6 alpha-particle counting. 7 activation analy. sis, 8 fission track counting. 9 and chemical separation techniques. 10

The early description of the fluorometric procedure for uranium, as given by Price et al.. Il forms the basis for the techniques described herein, although a number of specific improvements have been made.

Fluorometric uranium determination has been used routinely for analyzing medical and biological materials. 12 as well as for natural waters 13 and geological samples. 14 The latter applications are becoming increas. ingly important for uranium prospecting by hydrogeochemical methods 15 on the llational scale, where rapid, accurate, and costeffective analysis for uranium at the prb level is required for tens of thousands of samples.
Fluorometric procedures have also been applied to the determination of $8 \mathrm{e},{ }^{16} \mathrm{~B}, 17$ $\mathrm{Ca}^{18} \mathrm{Ga},{ }^{19} \mathrm{Ga},{ }^{20} \mathrm{Li}, 21$ rare earth elements. $22 \mathrm{n}, 23$ and $2 \mathrm{r}, 24$ s well as the application of fluorometry in vitamin analysis. 25 This list is not exhaustive. Many improvements have been made in the fluorometric determination of these elements. the description of which is beyond the scope of this document.

\section{EXPERIMENTAL}

\section{A. Apparatus and Reagents}

i. Platinum dishes (fig. I)

2. Pellet maker (fig. 1 and 5)

3. Nichrome wire screen (fig. 1)

4. Extraction apparatus (fig. 3)

5. Fusion burner (Fig. 2 and 4)

6. Air and propane regulators (Fig. 4)

7. Timer (Fig. 4)

8. Fluorometer (Fig. 6)

9. Sodium fluoride (t luorometric grats ucsa!

10. Other reagents ali of which are analytical-reagent-grade chemicals. 
B.

Preparation of Standards

National Bureau of Standards. SR.H

(Scandard Reference Hacerial) $9502\left(U_{3} 0^{\circ}\right)$ is used as the primary standard. A 1.179-9 portion of the SAH is dried for $1 \mathrm{~h}$ in on open crucible at $900^{\circ} \mathrm{C}$, cooled in a dessicater. dissolved in solucion of $10 \%$ nitric acid (HAO $)_{3}$ and $1 \mathrm{~s}$ sulfuric acid $\left(\mathrm{H}_{2} \mathrm{SO}_{4}\right)$, and diluted to 1 liter. This primary standard has a uranium concentrabion of $1.00 \mathrm{mg} / \mathrm{ml}$ which can be further dillited to match concencrations expected in semples being analyzed. When a new primary siandard is prepored, it is compared against the existing standard and submitted to other gioups for intralaboratory analysis.

c. Merhod

An aliquot of a liquid sample, or of a solution of a salid sample, is diluted and acidified to contain between 5 to $500 \mathrm{ng}$ $u / m I$ in 5 to $10 \% \mathrm{HNO}_{3}$. If ions are oresent which will interfere with the uranium fluorescence, en aliquet of the diluted sarple is salked with aluminium nitrate (AL ( $\mathrm{HO}_{3}$ ). $\left.9 \mathrm{H}_{2} \mathrm{O}\right)$ solubien and the uranium is expracied into ethyl acetele $\left(\mathrm{CH}_{3} \mathrm{CO}_{2} \mathrm{CH}_{2} \mathrm{CH}_{3}\right)$. Aliquots of elther the diluted sample or the exiracted sample are removed and iransferred onto mellets of lithium fluoride-satium fluoride (LiF-NaF) flux in platinum dishes. ihe pellets are then dried. fused, and allowed to cool, farming buttons. The thorescence of the butcon is measured using a Galvanek-Morrison fluoromeler.

D. Prepartion of Samples

Soil samples are ground to-100 mesh and mixad to produce homogenous sample. An aliquot of the soil is weighed and transferred into a $250-m$ a tefion besker, then digested using $20 \mathrm{~mL}$ of $\mathrm{HWO}_{3}$ and $50 \mathrm{~mL}^{2}$ af vif. During acid digestion the solution is evaporated to dryness on a hot plate and wet aghed wiln $\mathrm{HMO}_{3}$ and hydrogen peraxide $\left(303 \mathrm{H}_{2} \mathrm{O}_{2}\right)$ to dissolve any carbonaceous material which might be presens. After digestion the sample is diluted and acidified so the finel volume contains $10 \% \mathrm{HNO}_{3}$.
Biological samples are dried to constant welght, ground and nixed, and then created in the some monner as the soil samples. Aqueous samples received for uranium analysis are filered and acidified to contain $12 \mathrm{HMO}_{3}$.

\section{E. Interferences}

The quenching effect on uranium fluorescence is of greal concern when working with samples containing very low levels of uranfum and unknow." quantities of interferring ions. A list of the mare abundant elements of the corth's crust, and their effect on fluorescence, is shown in Table 1 . Solutions with ange of 0:1.25,000:1. 100.000:1, aro 200.000: 1 of element to uranium were pipetted dicecliy onlo fluoride pellets which were dried. lused. and cooled to deternine fluorescence and thus detect the quenahing effect of the added elements. Thu elements that had quenching effects atecreased fluorescence quantitatively with increased element concencration. The irend of the quenching effect of tho elements tested al the highest concentrotion retio

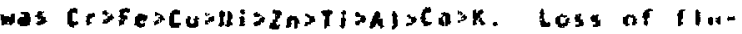
orescence was 1002 with Cr, 77t with Fe. 50 t with $\mathrm{Cu}$ and $\mathrm{Ni}$, and $36^{\mathrm{t}}$, wh $\mathrm{in}$. Pellet discoloragion appears to bo indicalive of high levels of quenching ions. When the direct method is used and discolared pellezs - re produced. the samples should be rerun using the $\mathrm{CH}_{3} \mathrm{CO}_{2} \mathrm{CH}_{2} \mathrm{CH}_{3}$ cxicaction procedure. f. Extraction procedure

Ten milliliters of luminum nitrate solution $\left.\mid 2 \mathrm{gAl}\left(\mathrm{NO}_{3}\right)_{3} \cdot 9 \mathrm{H}_{2} \mathrm{O} / \mathrm{mL}\right)$ is placed in a serew cap exeraction $25-m i$ yisl. An aliquot of somple is odded that witl yiefd an $\mathrm{CH}_{3} \mathrm{CO}_{2} \mathrm{CH}_{2} \mathrm{CH}_{3}$ solution that contains between 5 and 500 ng $\mathrm{U} / \mathrm{m}$ e. Two to ton milliliters of $\mathrm{CH}_{3} \mathrm{CO}_{2} \mathrm{CH}_{2} \mathrm{CH}_{3}$ are pipeiced rapidly into the vial. which is capped and shoien vigorously for $1 \mathrm{~min}$. The sampla volume and the amount of $\mathrm{CH}_{3} \mathrm{CO}_{2} \mathrm{CH}_{2} \mathrm{CH}_{3}$ used is $\mathrm{de}$ pendent un the expected uraniun concentration. 
The lour elements with the highest quenching efrect were added to uranium standords and the siandards anolyzed to determine the eflectiveness of the extraction procedure.

In evaluating the efficiency of the extraction procedure. the volume of sample andived is criticol. Is the quantity of Al( $\left(\mathrm{HO}_{3}\right)_{3}$. $9 \mathrm{H}_{2} \mathrm{O}$ is kent constant as the sample volume is increased. lite efficiency of the ext:action decreases. This study indicates that 1 mi is the maximum sample volume which should be used in the extraction with

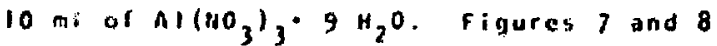
show the results oblained when the volume of standard was increased rom 1 la $6 \mathrm{mi}$ using two different concentralions of uranium.

The expected fluorescence decreased with increased roluthe of standard, indicaling incomplete catraction of the uranium into the $\mathrm{CH}_{3} \mathrm{CO}_{2} \mathrm{CH}_{2} \mathrm{CH}_{3}$. This $\mathrm{Has}$ probably due to in: efficient salling capabilities of the sluminum nitgate selution with volumes greater than 1 mit. of gtondard.

C. Preparation of Pellets fexr Fusion Tereney platinum distas are placed on a nichrotac wire screen ascopding tw the parcern sllown in cigs. I and 9. A tiax pellet is farmed, using, pellet maker. Iroth a nititure of $98 \%$ HaF -2 t if, and placed in each platinum dish. The tha pellets have an spproximale weight of $55 \mathrm{ma}$ each. The tesired aliquots of the bomples and ston-

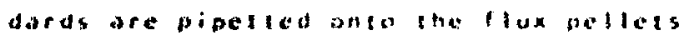
using a volume between $0.05 \mathrm{~m}$ a and $0.25 \mathrm{~m}$. depending urou lice surpected wroniune concentration. The standards used an each plove strould have uranium coucentralions that bracket the winium concenstrtion of the ramples on the sample olatel After all the standords and sumples have been pipetide. the nichrome sereen and the dishos are noved onlo a hot plate and allowed lo ory fur 15 to $20 \mathrm{~min}$. The flux pellets must dry completely before fusion or the flux will splatter from dish to dibh causind cross contamination of the samples.

\section{H. Fusion Procedure}

After the nichrome screen is placed on the fusion burner. the pilot light is ignited and the dit flow is adjusted to 1000 SCFH and approximately 80 gCFH of propane is added to the gas stream. The timer is set for 2 min and the propane flow is slowly readjusted until the flame is of the proper height and temperalure as shown in Fig. 10. Flame height diminishes as the screen becomes heated, and the procedure for properly adjusting the flame requires experiance before it can be done routinely. After 90 s the propane flow is decreased to approxi mately 50 SCFH, and the bubbles which have formed at the botiom of the dishes should rist and dissipale (fig. II). After 2 min fustion time, the propane and then the air are shut off.

The large variation in fluorescence of stand ids due to fluctuation during fusion prompted detailed investigation of fusion control. Very small changes in parameters of the gases during fusion were fcund to change the calibration curve as much as $90 \%$. Therefare, the effect of vorving the fusion time was studied at three measured temperatures $11190^{\circ} \mathrm{C}$ fig. $12,1260^{\circ} \mathrm{C}$ fig. 13 and $1420^{\circ} \mathrm{C}$ Fig. 141. Fluarescence in samples fusec at $1260^{\circ} \mathrm{C}$ appears to be rather insensilive to variations in the duration of the fusion: therefore, Enis is obviously the optimun temperature to fuse the pellets.

The results show that running single pellel standats and samples and assuming a constunt calibration curve can iniroduce substontial error in analysis of the samples. The review of literature on uranium anolysis revealed that many laboratories run sinnle pellet fusions giving litile consideration to variation during fusion. Another method evaluated was one in which multiple fusions used only one concentration for the standards run on the sample plate. This incorrectly assumes that the stondard curve passes through the origin, and this circumstance is frequencly not erue. The methods reviewed did not indicate any 
method that might be used for quality control for plate-by-plate or pellet-by-pellet fusion. The method that has been developed in this study eliminates the guessing of fusion conditions that has led to many erroneous results. It consists of running each fusion plate with the samples in duplicate and the two different concentrations of stanciards in triplicate. This method takes into account the variables that take place during fusion, arid eliminates the uncontrollable problem of slope variation of the calibration curve as a function of fusion conditions.

As soon as flux solidification is complete the screen is removed from the burner and placed on a heat-resistant surface. since the cooling rate affects the flworescence of the pellets, it is important to follow the same procedure in cooling each set of fused buttons.

\section{l. Calculations}

After cooling the plate of fused buttons for $15 \mathrm{~min}$, each peller is measured using a Galvanek-Morrison Fluorimeter (Fig. 6) at the lowest scale. A calibration curve is calculated by plotting instrument readings in microamperes vs concentration of uranium of the two standards. The calibration curve for this study was calculated using a program which used a weighted least squares fi: with the essociated uncertainties of the calibration points if two or more standard concentrations have been used. Allowing for the intensity and uncertainty of readings, the final uranium concentration and its uncertointy can be calculated. uncertainty of the readings can be determined two different ways. One is to take the variations of the readings on each set of duplicate samples of a fusion plate. the other is to determine variation on a large number of standards and apply on average variation to each sample and allow only a maximum spread in readings. A listing of the computer program is presented in the Appendix.

\section{J. Results and Discussions}

Uranium analyses of low-level natural water samples from Alaska and New Mexico were made by neutron activation 26 and $f$ uorometry to evaluate the accuracy of this procedure. The results of the comparison are shown in Table II. All analyses are standardized using solutions prepared from National Bureau of $s$ tandards Reference Material $950 a$.

Filtered and unfiltered samples were analyzed to evaluate potential differences introduced by suspended particulate mater. The unfiltered samples are analyzed by taking $20 \mathrm{ml}$ of the sample to dryness, dissolving the residue in $10 \% \mathrm{HNO}_{3}$ and pipetting directly onto the flux pellet. The filtered samples were filtered using 0.45 um MF-millipore (mixed esters of cellulose) filters. After filtration, $20 \mathrm{ml}$ of the filtrate was evaporated to dryness, and the sample residue was dissolved in $10 \% \mathrm{HNO}_{3}$ and pipetred directly onto the flux pellet.

The samples with uranium concentration above 0.3 ppb generally agree within the analytical uncertainties; but both the filtered and unfiltered samples showed higher variation below the 0.3 -ppb level. Samples with uranium concentrations less than 0.3 ppb are very close to the detection limits of the procedure, which probably accounts for the high variation.

The accuracy of this procedure was studied using onf wational Bureau of Standards SRM (Coal Fly Ash 4 1633) and two International Atomic Energy Agency Reference samples (\$467 and \#25). Different dissolution techniques were implemented in analyzing the samples to determine if one might prove superior. In general, the three dissolution techniques worked equally well (see Table 111 ). The samples with the higher uranium concentrations were diluted enough that quenching ions had little effeet on the direct method. The low standardin Table lll had little dilution which accounts for the low results probably due to quenching. 
As a measure of accuracy, the recovery percentage is calculated using the following formula: \& Recovery = $\frac{\text { Measured Value }}{\text { Actual Value }} 100$. As a measure of precision, twice the standard deviation (20) from the mean of replicate values is determined (each group of six is considered one replicate group). A mean for all analysis (excluding the deviant fly ash) and a mean value for only those samples dissolved in HF-HNO 3 is reported in Table IV for each parameter. Each value has associated with it a $2 \sigma$ which is a measure of the population distribution.

$\sigma=\sqrt{\frac{N_{i} \sum\left(x_{i}-\bar{x}\right)^{2}}{N-1}}$ and a $2 \sigma_{x}\left(\sigma_{\bar{x}}-\frac{0)}{\sqrt{H}}\right.$. which

is a measure of how well the mean value is known.

\section{ACKNOWLEDGHENTS}

The author wishes to thank E. S. Gladney whose patronage and assistance made this paper possible. Also, I would like to thank Davio Curtis for his critical comment on the maniscript and Priscilla Jose for her assistance with the fluorometric analysis.

\section{REFERENCES}

1. Rodden, C. J. and J.C. Harf, Nazional Huclear Energy Series, Div. VIIl, I, "Analvical Chemistry of the Manhation Project,"1950, pp. 122-135.

2. Duval, C.. Anal. Chim. Acta 3, 335 (1949).

3. Sill, C. W. and H. E. Peterson, Atomic Energy Commission report BH-RI-4882 (June 1952).

4. Crouthame 1, C. E. and C. E. Johnson, Ana 1. Chem. 24, 1780 (1952).

5. Carson, W. M.. Anal. Chem. 25. 466 (1953).
6. Bloche, E., P. Leveque, and $H$. Provisor, Bull. Soc. Chem. France 16, 83 ( 1949 ).

7. Campbel1, E. E., B. M. Head, and M. F. Miligan. Los Alamos Scientific Laboracory report LA-1920 (June 1955).

8. Makintosh, $W, O$, and $R$. E. Jervis, $A E C$ of Canodo, Ltd.. report AECL-48) (Apri) 1957).

9. Carpenter, B. S, and C. H, Cheek, Anal. chem. 42. 121 (1970).

10. Rodden, C. J., Anal. Chem. 25, 1598 (1953).

11. Price, G. R., R. J. Ferretti, and $S$. S. Schwartz, Anal. Chem. 25. 322 (1953).

12. Meuman, W. F., R. W. Fleming, A. B. Carlson, and $N$, Glover. J. Biol. Chem. 173. $41(1948)$.

13. Thatcher, L. L. and F. B. Barker, Anal. Chem. 29. 1575 (1957).

14. Adams, J. A. S. and W. J. Maeck, Anal. Chem. 26. 1635 (1954).

15. Boyle, R. W., E. H. W. Hornbrook, R. J. Alian. H. Dyck, and A. Y. Smith, "Hydrochemical Hethods - Appljcation in the Canadian Shield", presented at CiM 73rd Annual General meeting. Quebec, Canada. April 1971.

16. Laitinen, H. A. and P. Kivalo, Anal. Chem. 24, 1467 (1952).

17. White, C.E., A. Weissler, and D. Busker, Anai. Chem. 19, 802 (1947).

18. Eveim, N, and L. A. Reber, Anal. Chem. 26. $836(1954)$.

19. Bradacs, L. K., F. Feigl, and F. Hecht, Microchem. Acta 1954. 269 (1954).

20. RaJu, H. A. and G. G. Rao, Hature 174. $400(1954)$.

21. White, C.E., M. S. Fletcher and J. Parks. Anal. Chem. 23. 478 (1951).

22. Prizibram, K. Nature 139. 329 (1937).

23. Merritt, L. L., Ind. Eng. Chem. Anal. Ed. 16, $758(1944)$.

24. Alford, W. C., L. Shapiro and C. E. White, Anal. Chem. 23, 1149 (1951).

25. Kodicek, E.. Analyst $\underline{72}, 385$ (1947).

26. Gladney, E. S.. J.H. Owens and J.W. starner. Anal. Chem., in press, 1976. 
sune $z$

obewinzo erect of unusum puosescrace

10 ngu/redret

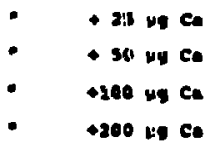

20 ngu/raliet

- 25 us $\mathrm{ML}$

- $\quad 50$ ug AL

- +200 ug a

- 4200 ug AL

$10 \mathrm{nou} / \mathrm{pellat}$

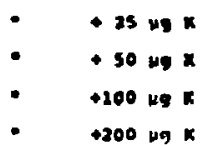

so mugreliet

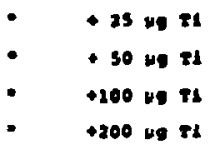

10 ng̣/rellet

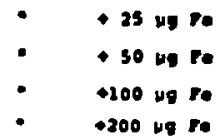

10 nov/Poldet

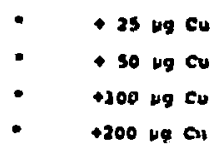

$10 \mathrm{ngu/periet}$

$$
\begin{aligned}
& -\quad 25 \text { ug ML } \\
& +\quad+50 \text { ug ML } \\
& -\quad+100 \text { ug ML } \\
& +200 \text { ug ML }
\end{aligned}
$$

$10 \mathrm{ngu} / \mathrm{pollot}$

$$
\begin{aligned}
& -\quad+25 \text { ug Cr } \\
& -\quad+50 \text { us Cr } \\
& -\quad 400 \text { ug Cr } \\
& -\quad \downarrow 200 \text { uq Cr }
\end{aligned}
$$

20 ngu/ratet

- 25 49 $2 n$

- 50 ng in

- 4200 ug $\mathrm{In}$

- $\$ 200$ 49 8 n

$.62 \times .03$

.258 .01

.56 .04
Gedinge ere in Mleroamiere reat

$.72=.03$

$.71 . .02$

.718 .02

$.67 . .64$

.05 .01

$.61 . .02$

.61 .03

.621 .03

.501 .04

.561 .03

.52 . .02

.40 .02

$.35 \times .02$

.578 .03

.551 .02

.639 .02

.63 1.05

$.62=.02$

$.57+.03$

$.651,03$

.451 .03

$.37 \times 0.02$

.231 .01

.491 .02

.409 .02

.32 .03

.33 .01

.67 .07

$.52 . .03$

.431 .01

$.32+.02$

$.20 . .03$

.601 .01

.261 .02

.26 .02

.00 .01

.021 .01

$.62 \pm .02$

\begin{tabular}{|c|c|c|c|c|}
\hline \multirow{3}{*}{$\begin{array}{r}\text { areste }-2 \\
2\end{array}$} & $\frac{94481}{x}$ & 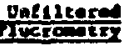 & \multicolumn{2}{|c|}{ 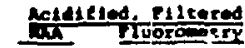 } \\
\hline & 0.4480 .01 & 0.2420 .05 & 0.7429 .65 & 0.5320 .01 \\
\hline & 0.6080 .20 & 0.2610 .05 & 0.4190 .06 & $0.58: 0.08$ \\
\hline 3 & 2.480 .1 & 1.6710 .00 & 1.610 .2 & 2.700 .2 \\
\hline 4 & 0.0410 .04 & 0.0410 .00 & 0.2220 .05 & 0.1710 .17 \\
\hline 5 & $0.27 \pm 0.06$ & 0.2710 .17 & $0.21 \div 0.05$ & 0.0420 .02 \\
\hline 6 & 0.3400 .07 & 0.3010 .80 & $0.26 \pm 0.05$ & $0.23=0.05$ \\
\hline 7 & 0.7610 .07 & 0.2310 .12 & 0.1010 .03 & $0.23: 0.00$ \\
\hline - & $0.05 \times 0.05$ & 0.2480 .07 & 0.0320 .05 & $1.02=0.02$ \\
\hline 5 & 0.22100 .06 & 0.1580 .08 & 0.3120 .05 & 0.4110 .13 \\
\hline 10 & 0.2710 .07 & 0.0010 .08 & $0.21=0.05$ & $0.03 \div 0.02$ \\
\hline 12 & $0.05=0.05$ & 0.1110 .00 & $0.02=0.04$ & $0.02 \times 0.02$ \\
\hline 12 & 0.1790 .08 & 0.0410 .00 & 0.1510 .05 & 0.0210 .02 \\
\hline
\end{tabular}

.62 .01

.551 .03

.451 .03

.3) 1.08

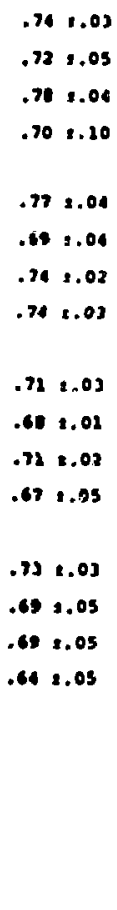

Tace 6

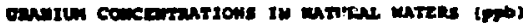

\begin{tabular}{|c|c|c|c|c|}
\hline & & mis & $\begin{array}{l}\text { IAEA } \\
\text { OA67 }\end{array}$ & $\operatorname{lakA}_{125}$ \\
\hline & & $\cot$ & $\operatorname{Pg}$ & $\operatorname{sen}$ \\
\hline & orted veluet & 11.610 .2 & $129: 12$ & 1102550 \\
\hline & Jetion pecker & $27.3 \div 0.9$ & $125: 13$ & $1220: 160$ \\
\hline $\mathbf{2 1}$ & Glans sodker & 13.032 .4 & 11411 & 1200200 \\
\hline 3) & $\mathrm{Ma}_{2} \mathrm{O}_{2} / \mathrm{MeOH}$ rusion & $14.0: 4.3$ & $111: 1$ & $1020=20$ \\
\hline 41 & Dicece Tefion couker & $5.7 \times 1.0$ & $123: 6$ & 1010:35 \\
\hline
\end{tabular}

now mateo - 1

36. 12. 20. 13.

11. 1. 0.112 .0

$0.510 .0 \quad 0.2 \div 0.0$

2.310 .22 .010 .5
JABLE III

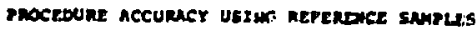

1) $10 \mathrm{ml}$ Nitile Acid, 30 el Hydeofluoric Acte

2) $20 \mathrm{ml}$ Mitrie Aelo, $5 \mathrm{ml}$ sulfurle Aelo, $5 \mathrm{ml}$ Hydrofluorie Asit.

3) 59 sodhun peraxide, I 9 sodiun lydrontde in Nickel criteible $4.900^{\circ} \mathrm{C}$.

4) 10 al Mitrle Metd, 30 al Mydrofluoric acta byposolng ethyl acetele extrection.

THI: IV

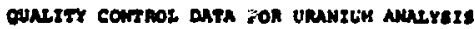

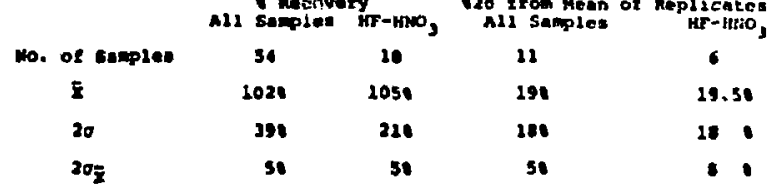




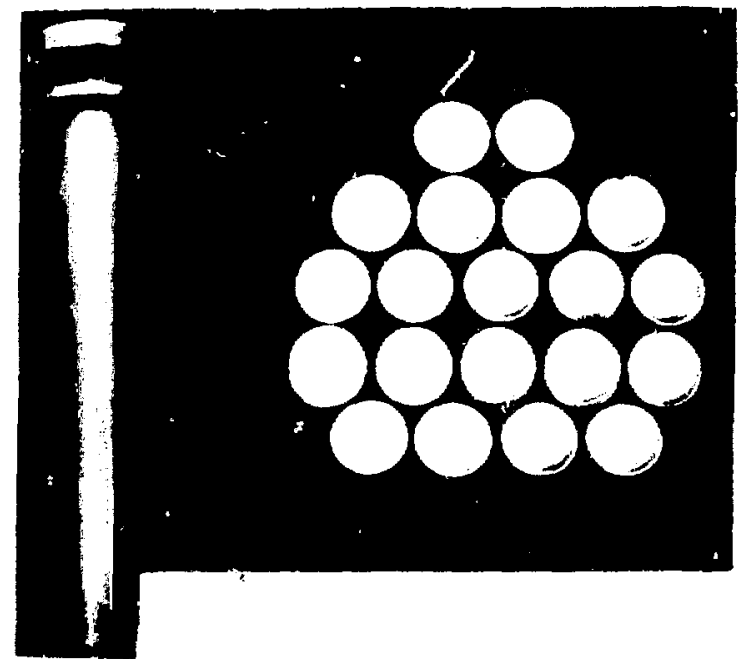

Fig. 1. Platinum dish arrangenont on nichrome screen.
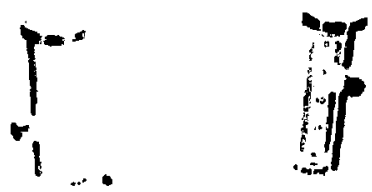

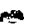

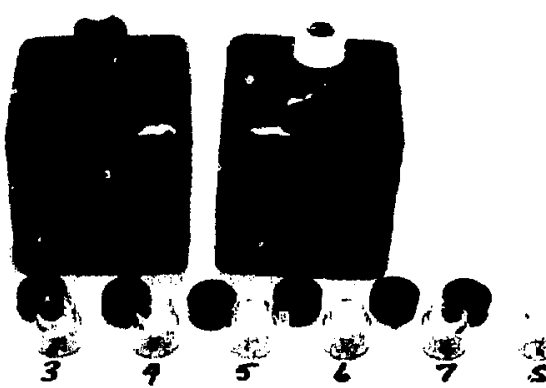

Fig. 3. Extraction apparatus.

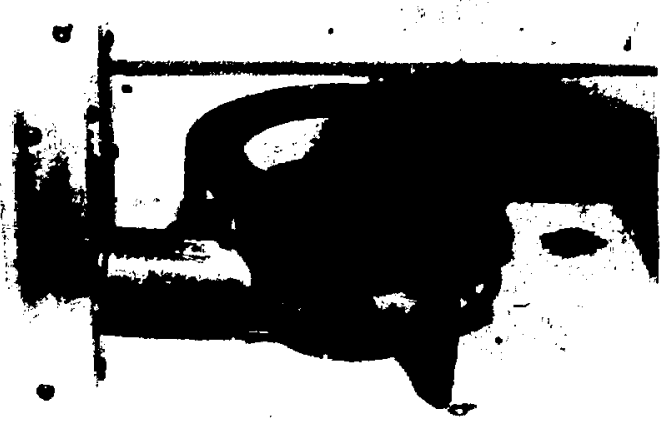

Fig. 2, Fletcher Fusion Company.

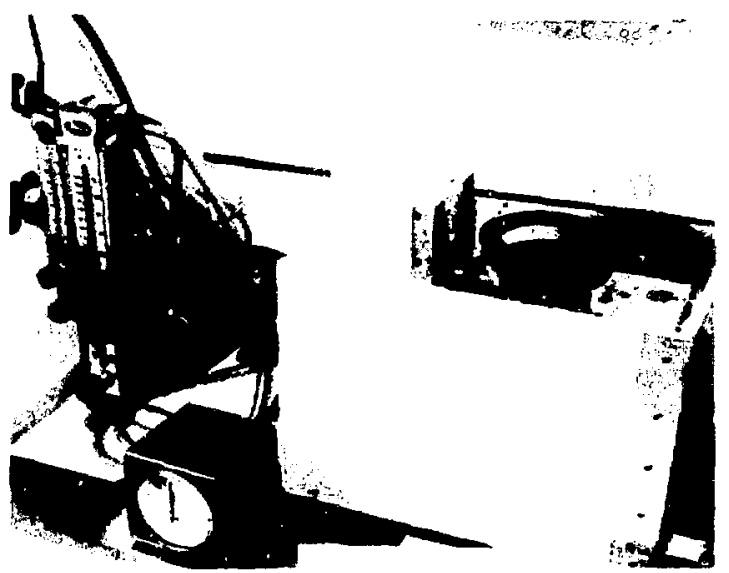

Fig. 4. Fusion apparatus.

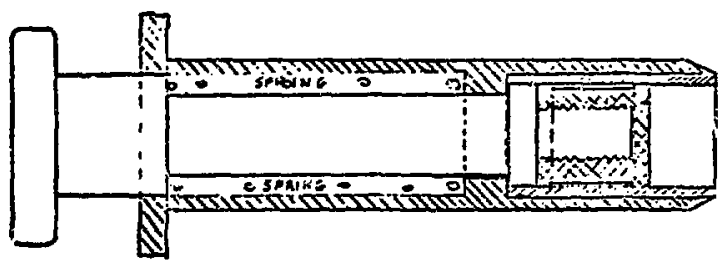

Fig. 5. Flux pellei apparatus. 


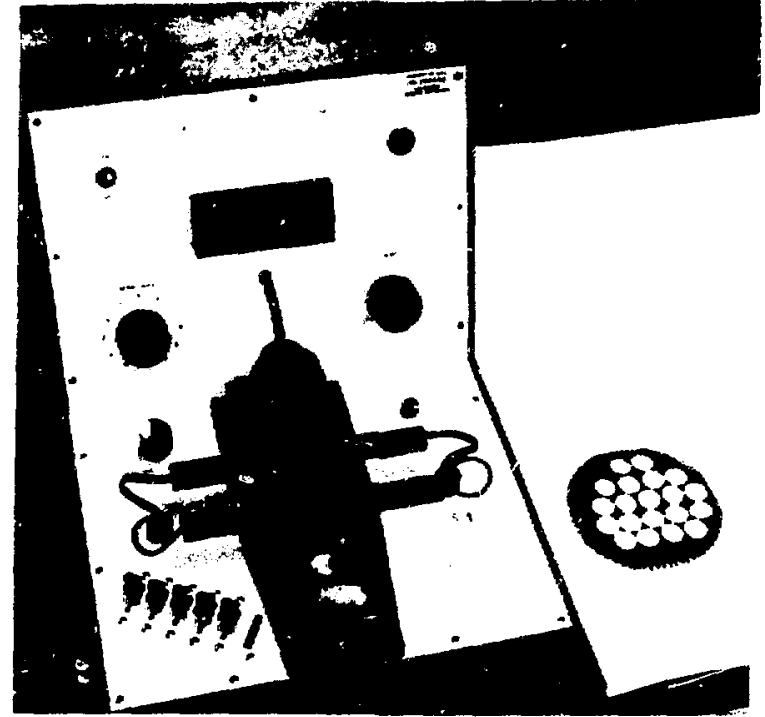

Fig. 6. Fluorometer and fused pellets.

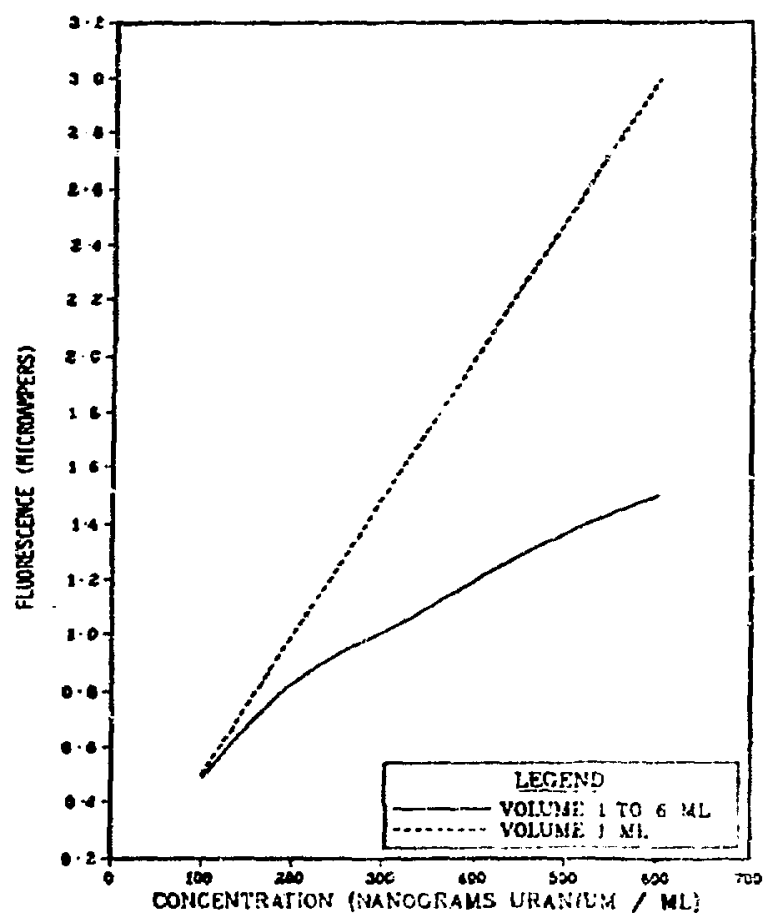

Vig. 7. Fluorescence change due to volume chanje.

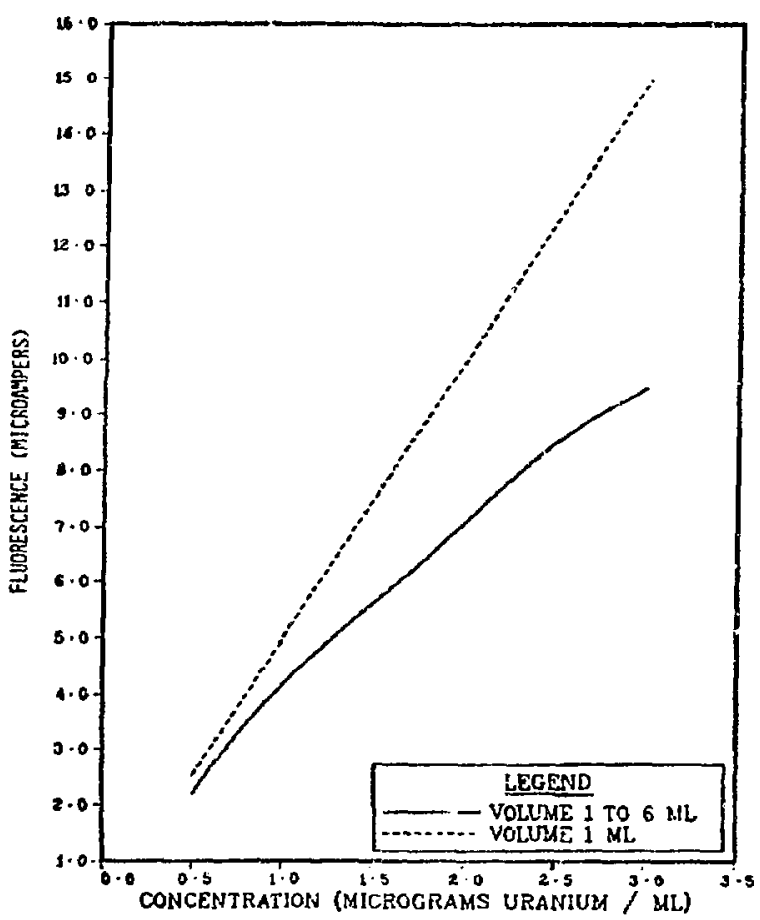

Fig. 8. Fluorescence charige due to volume change. $s_{1}$ - Standards (low value) 3 per plate.

$S_{2}$ - Standards (high value) 3 per piate.

1-\$7 samples 2 per sample per plate.

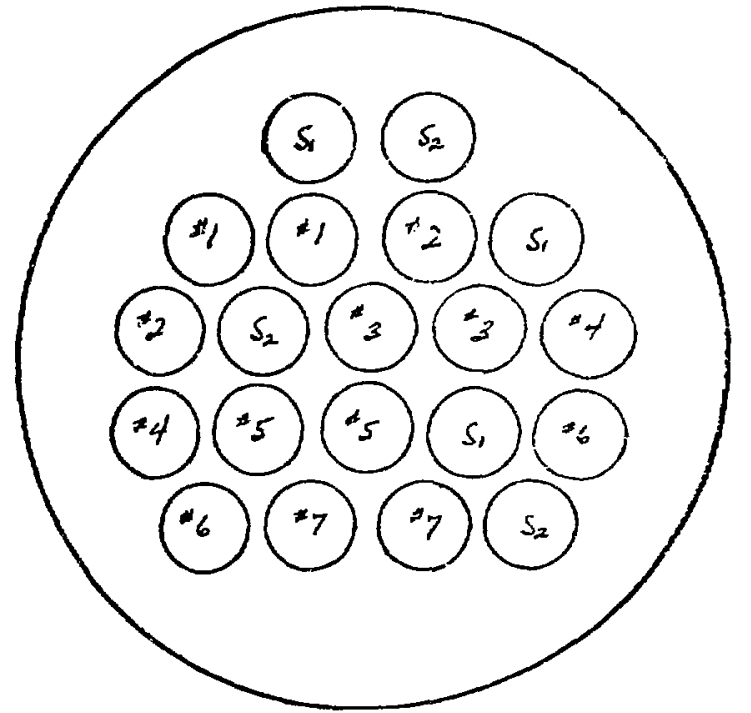

Fig. 9. Fusion plate arrangement. 


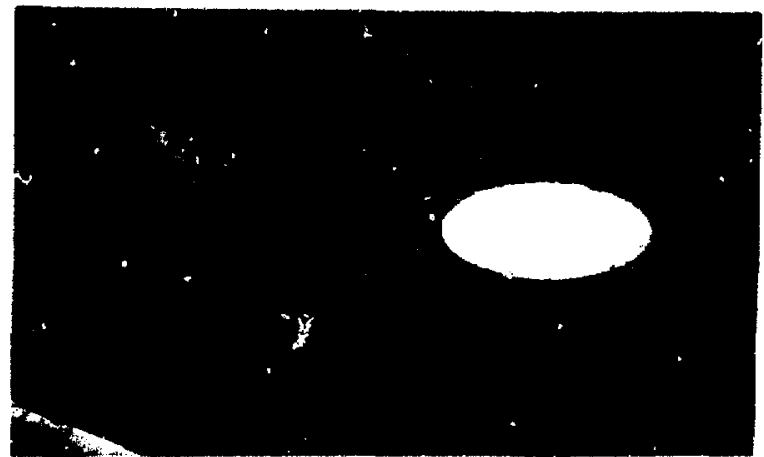

Fig, 10. First stage of fusion $1.5 \mathrm{~min}$.

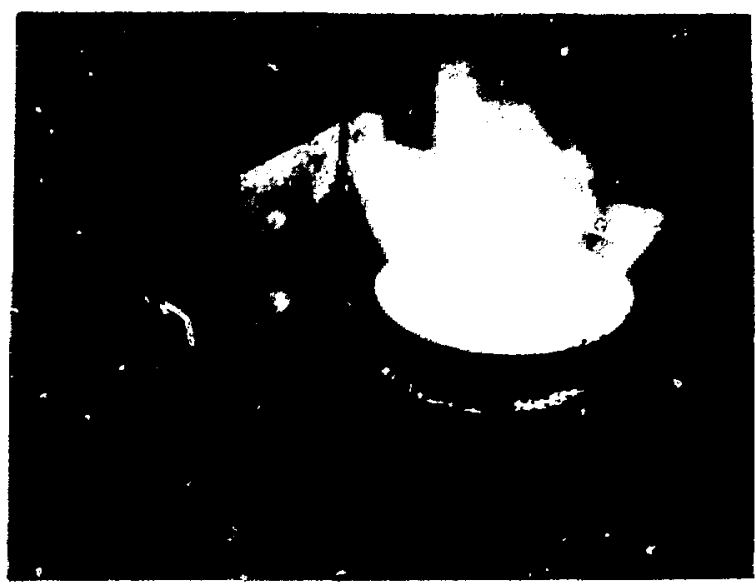

Fig. 11. Sevond stage of fusion $0.5 \mathrm{~min}$.

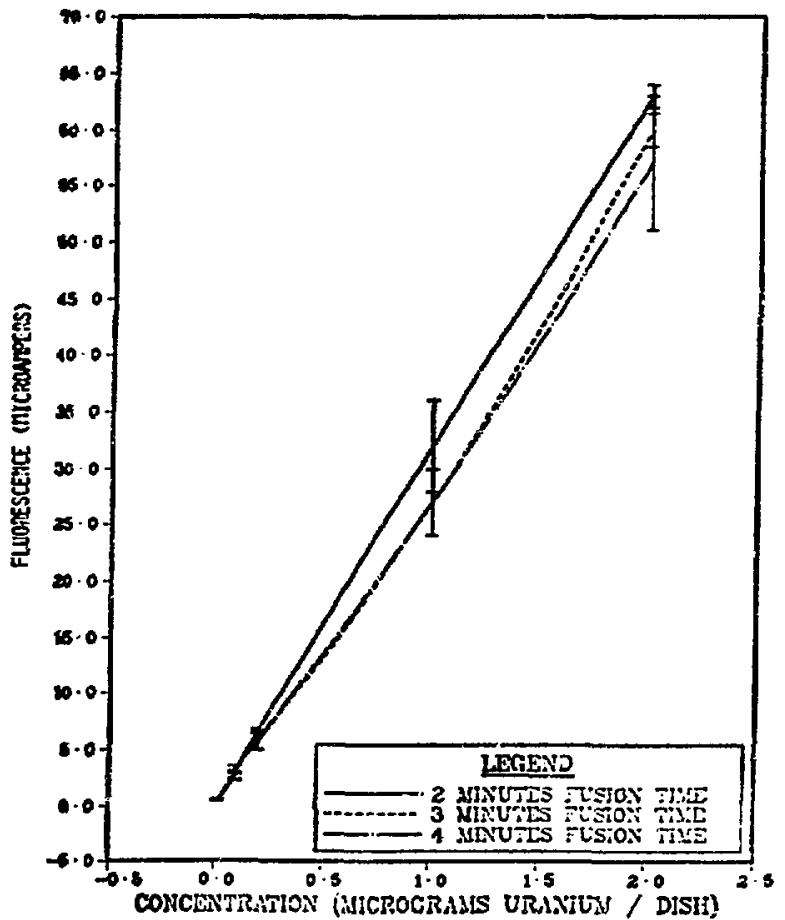

Fig. 13. Fluorescence change due to change in fusion time at $1260^{\circ} \mathrm{C}$.

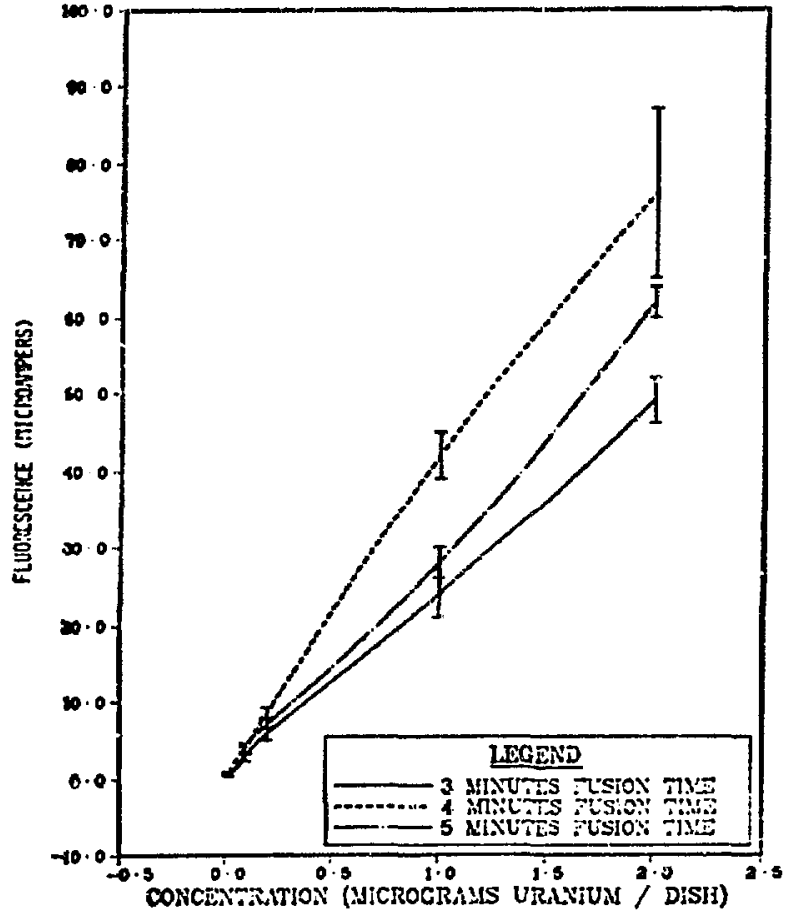

Fig. 12. Fluorescence change due to change in fusion time at $1190^{\circ} \mathrm{C}$. 


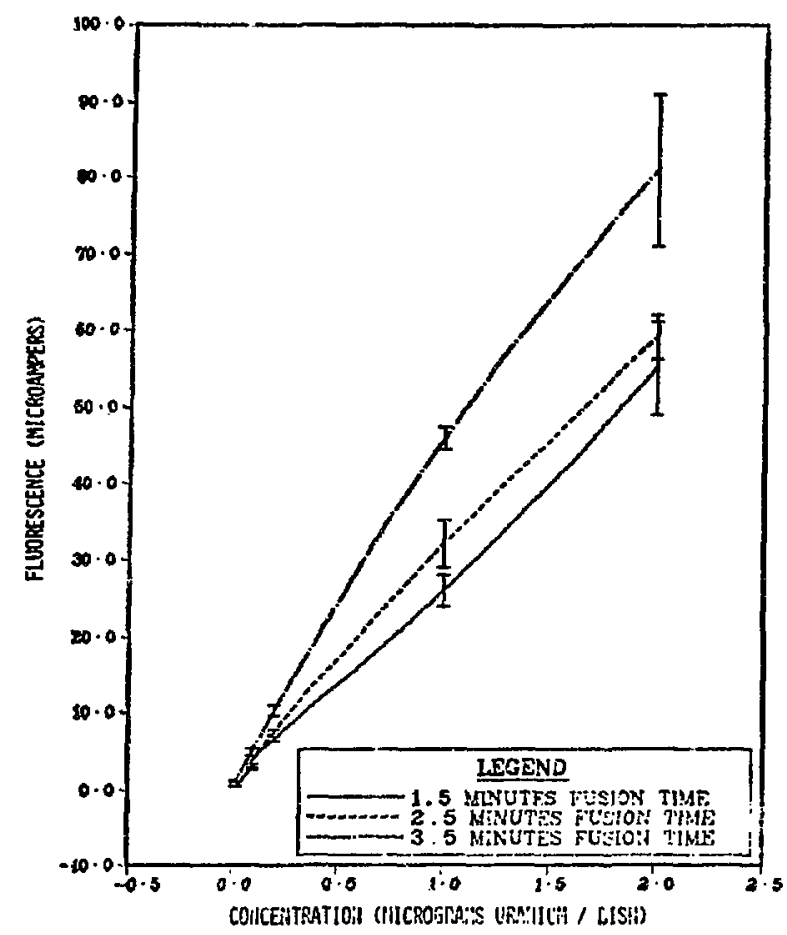

Fig. 14. Fluorescence change due to change in fusion time at $1420^{\circ} \mathrm{C}$.

APPENDIX $\lambda$

PROGRAM IN BASIC LANGUAGE USED FOR CONCINTRRIIUUN CALCLLATIONS

LI $\geqslant$ r

$75 \cdot 11 \cdot 05 \cdot 13.53+45$.

PRDBRTM LITHEG

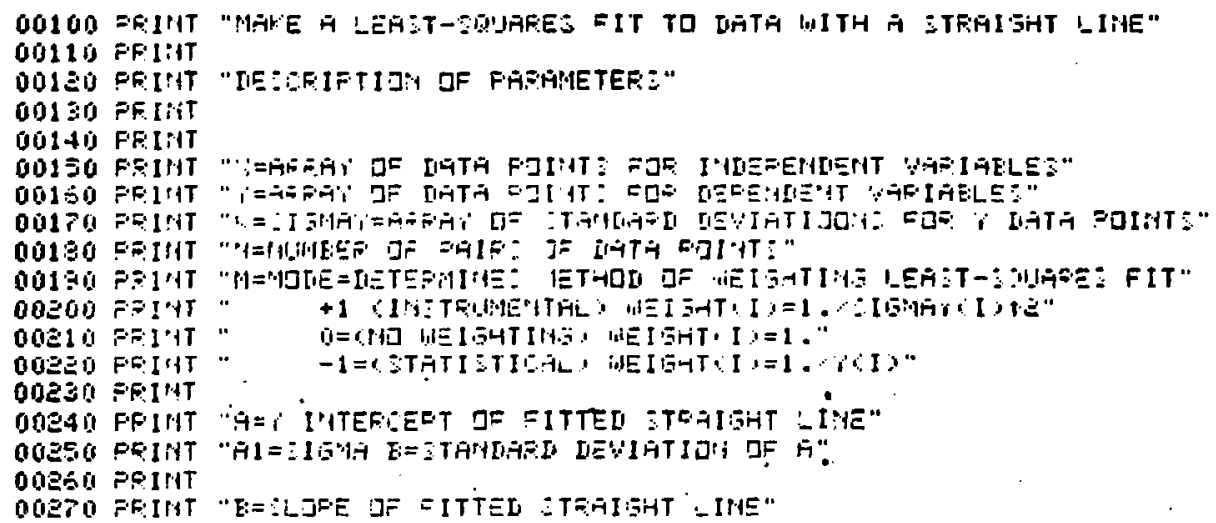




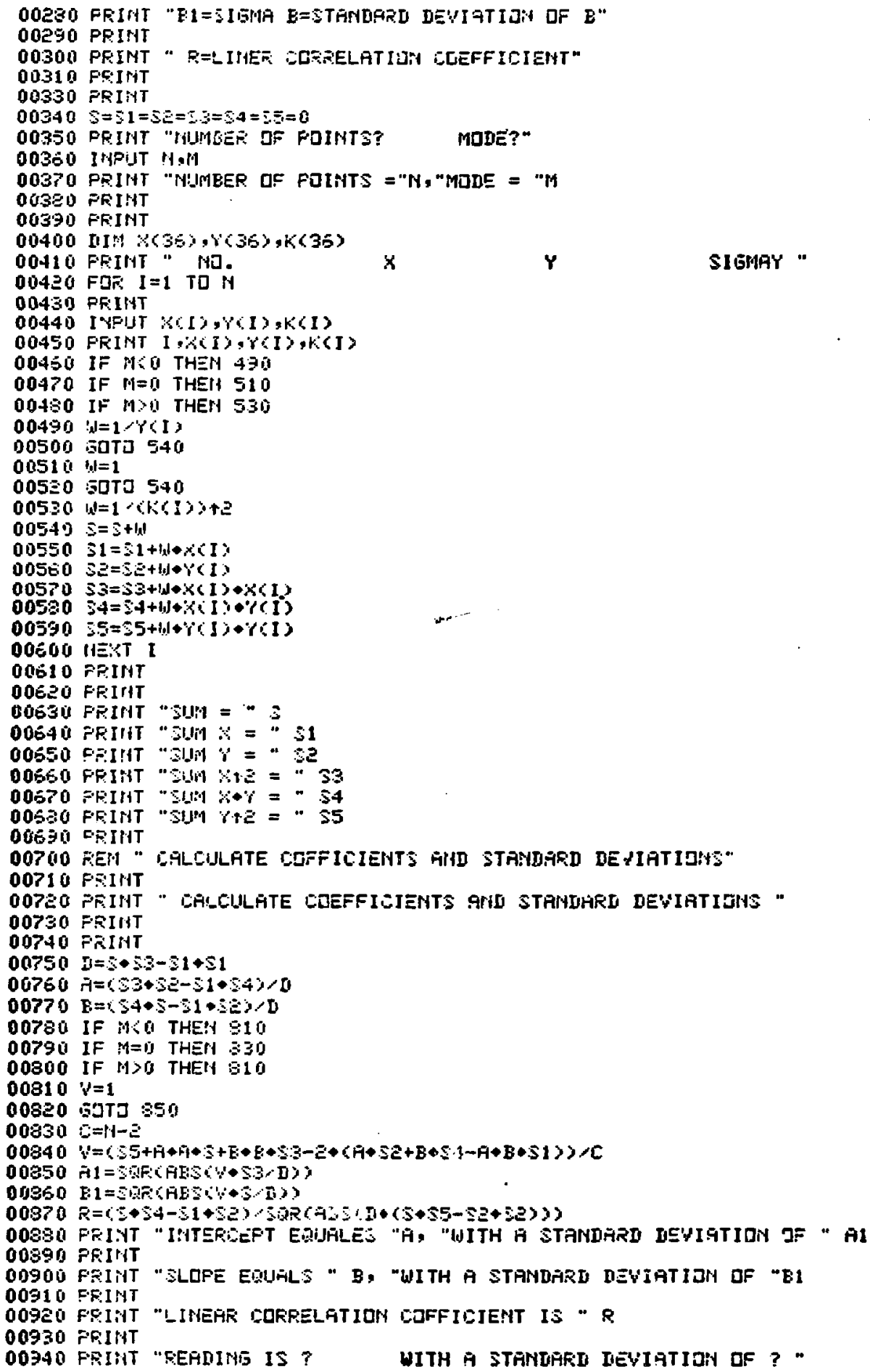


00945 PRINT

00950 IHAUT $C, \mathrm{CL}_{1}$

00955 If $0=9999$ THEN 310

00950 C $E=(S-A) \cdot \mathrm{B}$

$00970 \mathrm{II}=1 \mathrm{DE}+(((\mathrm{Cl}) \mathrm{C})+2+(\mathrm{B} 1-\mathrm{B})+2)+0.5)$

00980 PRINT

00970 FRINT “ REAIINE IS" $E$, “WITH A STAHDARD DEVISTICN DF "CL

01000 DRINT - CDIUENTPATIDN OF "CE, "WITH ERRER DF "DI

01010 50Td 945

01020 STLP

01030 ENG

READY 